\title{
LAS ANTIGUAS COLECCIONES ARQUEOLÓGICAS DE YUCATÁN \\ EN EL MUSEO AMERICANO DE HISTORIA NATURAL
}

\author{
Adam T. Sellen \\ Centro Peninsular en Humanidades y Ciencias Sociales, UNAM \\ LYNNETH S. LOWE \\ Centro de Estudios Mayas \\ Instituto de Investigaciones Filológicas, UNAM
}

\section{Introducción}

Este trabajo forma parte de un proyecto mayor cuyos objetivos principales consisten en hacer una caracterización de la práctica del coleccionismo arqueológico llevado a cabo en la península de Yucatán durante el siglo xix, y en describir cómo dicha actividad dejó su huella en las instituciones culturales tanto del ámbito local como nacional. ${ }^{1}$ Para ello intentamos establecer quiénes fueron los principales coleccionistas en la región, con miras a la investigación del destino final de sus acervos, así como la relación científica, social y mercantil sostenida con los viajeros extranjeros que llegaron a México en busca de conocimientos y materiales arqueológicos.

El coleccionismo arqueológico puede definirse como el proceso de reunir de manera sistemática objetos antiguos y la información asociada (arqueológica), aunque para fines del proyecto nos parece conveniente ampliar tal definición para poder incluir también otros datos que documenten la trayectoria histórica de los artefactos a partir de su descubrimiento, como son el análisis, la interpretación y la exhibición del objeto. En ese sentido, deseamos enfatizar - como lo hace Bruce Trigger (1985) - que el estudio de la historia de la disciplina arqueológica, del desarrollo de sus procesos y métodos, no es algo incidental en esta disciplina, sino una contribución vital para que se realice de manera más eficaz y autoconsciente (Trigger, 1985: 232). Al entender cabalmente cómo el hecho de coleccionar influyó en la construcción de los fundamentos de la disciplina, así como en la génesis de las instituciones culturales que complementan esta

\footnotetext{
${ }^{1}$ Este proyecto se titula "El patrimonio perdido. Historia del coleccionismo arqueológico en la península de Yucatán en el siglo xIx", y es apoyado por la UNAM, a través del programa PAPIT, No. IN-401208.
} 
actividad, será posible alcanzar una comprensión más completa de las ideas y las interpretaciones que conforman nuestro saber sobre el pasado.

A partir de una estancia en Nueva York el verano pasado, el responsable del proyecto visitó el Museo Americano de Historia Natural (AMNH) con el fin de revisar sus acervos arqueológicos y la documentación asociada. En general, este museo no cuenta con abundantes objetos prehispánicos de Yucatán; sin embargo, las pocas piezas que allí resguardan resultan representativas, no sólo de la cultura antigua sino de los diversos episodios de exploración emprendidos por viajeros extranjeros; también resguarda colecciones arqueológicas reunidas por yucatecos. El 12 de diciembre de 1899 el museo abrió al público la Sala Mexicana (Mexican Hall) donde, a pesar de su nombre, se presentaban, además de gran cantidad de piezas de México, de otros países centroamericanos, como Guatemala, Honduras y Nicaragua. La mayor parte de la exhibición consistía en reproducciones de moldes sacados de diversos monumentos del área maya, en particular de Copán, gracias a un acuerdo con el Museo Peabody de la Universidad de Harvard (figura 1).

Hay que recordar que el AMNH nunca tuvo un proyecto arqueológico específico en Yucatán, como el que emprendiera el Museo Peabody en Chichén Itzá, a través de Edward Thompson, o el magno proyecto de la Institución Carnegie de Washington, que se inició en el mismo lugar en 1921; no obstante, el museo logró extender una amplia red sobre la región a través de terceros que depositaron allí modestas colecciones reunidas a lo largo del siglo xix. Participaron muchos individuos en esta empresa, como los viajeros franceses Désiré Charnay y Augustus Le Plongeon, y el alemán Eduard Seler. Estos últimos fueron patrocinados por el duque de Loubat, el neoyorquino Joseph F. Loubat, quien era un ferviente aficionado de la arqueología americana, y que gracias a su considerable fortuna logró impulsar las carreras de muchos investigadores, así como canalizar gran cantidad de artefactos americanos a los museos extranjeros (Balkansky, 2005: 89). En concierto con su patrocinador Loubat, fue Eduard Seler quien logró proporcionar al AMNH la mayor cantidad de colecciones procedentes de México, y en particular de Yucatán (Putnam, 1900: 20). En realidad, Seler respondía ante dos amos, ya que además era curador del área de Las Américas en el Museo Etnográfico de Berlín, y reunía entonces ejemplares tanto para el duque de Loubat como para su propio museo. A pesar de ello, logró mantener las relaciones claras, y siempre encontró la manera de dividir equitativamente las colecciones entre ambas instituciones.

\section{Las colecciones tempranas}

Al parecer, la colección más temprana de la península de Yucatán fue la de un estadounidense, el doctor Edwin Davis, aficionado a la arqueología y miembro de la Sociedad Etnológica Americana. En 1831 comenzó a excavar los montícu- 
los de la cultura Hopewell, en Ohio, y logró reunir un considerable conjunto de artefactos de esta región, pero además tenía en su colección ejemplares de diversas partes del mundo, incluyendo tres piezas de cerámica procedentes de Yucatán. Sin embargo, ignoramos si Davis recibió dichas piezas como obsequio o si él mismo visitó la península en algún momento. Lo interesante en este caso es la información asociada, ya que la colección está acompañada de una detallada lista de las piezas — clasificadas según su propio criterio-, que el doctor proporcionó al Museo de Historia Natural cuando completó su venta en $1874 .^{2}$ En la introducción al inventario él rechazaba la clasificación estándar que se utilizaba en aquel siglo, propuesta por el danés Worsaae en 1836 (obra traducida al inglés en 1849), la cual empleaba las categorías de piedra, bronce y hierro, bajo la argumentación de que las culturas americanas no conocían dichos metales. Clasificó entonces el material según la calidad de su manufactura. Davis, y muchos de sus homólogos mexicanos, como los coleccionistas oaxaqueños (Cfr. Sellen, 2005), se dieron cuenta de que la arqueología americana era distinta de la del Viejo Mundo y que, por lo tanto, se necesitaba de otras herramientas conceptuales para su comprensión.

Otro donador temprano de piezas arqueológicas peninsulares fue el francés Emile Des Marets. En 1895, él proporcionó seis vasijas de cerámica al AMNH provenientes de la hacienda de "Yabucic", propiedad de Lorenzo Peón, que distaba una legua del pueblo de Acanceh. Según este coleccionista, se encontraron varias tumbas al cultivar el terreno, y junto con las piezas cerámicas hallaron "huesos, oro y plata", aunque no se conservan evidencias de ello. ${ }^{3}$

Además, el museo contaba con un conjunto de 21 moldes de papel (squeeges, como se conocían en inglés en aquel tiempo) de diversos bajorrelieves y esculturas, realizados por el explorador francés Désiré Charnay, bajo el patrocinio del duque de Loubat. La gran mayoría de estos moldes fueron tomados en Chichén Itzá durante su tercera visita, en 1880 , donde según las palabras del propio explorador había reunido "más de sesenta metros cuadrados de bajorrelieves escogidos entre los más interesantes y los más hermosos" (Charnay, 1884: 402), Para transportar las estampas sin dañarlas, fueron cubiertas de lienzo negro impregnado de cautchuc (hule) y llevadas en angarillas sobre los hombros de los habitantes de Pisté. A pesar del enorme esfuerzo para realizar y transportar estas réplicas al museo de Nueva York, donde fueron exhibidas en la impresionante Sala de las Estelas, hoy en día existen pocos ejemplares y muchos fueron destruidos al desmantelar la exhibición. ${ }^{4}$

\footnotetext{
2 "Catalogue of American Antiquities Collected by Dr. Edwin H. Davis", Archivo Histórico del AMNH, Acc. No. 1869-90-15.

${ }^{3}$ Emile Des Marets, Archivo Histórico del AMNH, Acc. No. 1895-31.

${ }^{4}$ Comunicación personal, Elise Alexander, curadora asistente, AMNH, 3 diciembre 2008.
} 
Una de las colecciones más interesantes de la región fue producto de las exploraciones del célebre viajero John Lloyd Stephens, escritor estadounidense que viajó a Yucatán entre los años 1841 y 1842 en compañía del talentoso dibujante y arquitecto inglés Frederick Catherwood. La narrativa de su viaje Incidents of Travel in Yucatán, así como las espléndidas láminas que registraron diversas vistas de las ruinas, sin duda constituyen un parteaguas en la historia de la arqueología americana, ya que a partir de entonces se abandona la especulación sin fundamento y se entra en una época que Willey y Sabloff (1974: 64) designaron como el Periodo Clasificatorio-descriptivo. Además de la intención de producir un best seller, uno de los propósitos de estos viajeros fue reunir una muestra representativa de artefactos, con el fin de exhibirlos en museos particulares en los Estados Unidos, y financiar así futuras exploraciones con el monto de las entradas. Con tal propósito, a lo largo de su recorrido por la península recolectaron objetos prehispánicos de diversos materiales, incluyendo algunos dinteles de madera ricamente esculpidos de los sitios de Uxmal, Kabah y Labná. Al terminar su viaje, trasladaron la colección a Nueva York, y colocaron las piezas como parte de un curioso espectáculo construido por Catherwood en la calle Broadway, llamado el "Panorama de Jerusalén". Poco después del estreno de esta sección de exóticos artefactos americanos el edificio se incendió, y tales evidencias únicas de la antigua cultura maya se convirtieron en cenizas (Von Hagen, 1990: 255). Felizmente, una parte de la colección de Stephens pudo salvarse, unas cuantas piedras que llegaron con retraso en una embarcación después del desastre. Por razones desconocidas, Stephens no menciona este suceso en su libro, aunque la historia de estas piedras afortunadas ha sido relatada en varias publicaciones en inglés (Spinden, 1920; Dauterman, 1939; Von Hagen, 1947: 231-232; Roberts, 2000: 551). Consideramos que este suceso merece ser destacado aquí también, sobre todo para integrar las imágenes que forman parte del expediente del museo.

Cuando llegaron las piezas — una colección de catorce piedras esculpidas procedentes de Kabah y Uxmal-, fueron entregadas por Stephens a su gran amigo John Church Cruger. Él las colocó empotradas como parte de una curiosa construcción hecha de lajas de piedra de factura neogótica, en un extremo de su finca particular, ubicada en una isla sobre el río Hudson, unas cien millas al norte de la ciudad de Nueva York (figura 2). En el archivo del museo todavía se conservan varias fotografías, en las cuales se aprecian tales piezas integradas a la estructura isleña en pleno invierno (figura 3). Las esculturas permanecieron expuestas a la intemperie unos cincuenta años, hasta que en el verano de 1899 , el presidente del Museo Americano de Historia Natural, Morris K. Jessop, tuvo noticia de su existencia e inició los trámites para su traslado al museo con el objeto de incorporarlas a la nueva Sala Mexicana. No obstante, esto no se logró sino hasta dos décadas después, ya que las hijas de Cruger se resistían a esa medida. En su correspondencia con el museo se deja entrever que ellas buscaban al mejor 
postor para su venta. ${ }^{5}$ Finalmente, el curador Herbert J. Spinden logró adquirir las piezas en 1919, y hasta hoy día se exhiben en la sala del AMNH.

Los monumentos procedían de dos sitos arqueológicos de la región Puuc: la estatua y los elementos decorativos vienen de la Casa del Gobernador, en Uxmal (figura 4), mientras que las dos lápidas en bajorrelieve son de Kabah. Estas últimas funcionaban como jambas y pertenecían a la Estructura $2 \mathrm{~A} 3$ de la plaza del Mirador, correspondiente al estilo Mosaico, fechado entre 830 y 980 d.C. (Pérez de Heredia, 2000: 34-35). Stephens relató con detalle su descubrimiento:

\begin{abstract}
Este edificio sólo tenía una puerta casi del todo obstruida, y al pasar por ella me llamó la atención el ángulo saliente de un plumaje, que casi todo estaba enterrado, esculpido en uno de los quiciales del marco. Inmediatamente me supuse que era un tocado y que debajo habría una figura humana esculpida. También esto era nuevo, pues los marcos de todas las puertas que hasta entonces hubiésemos visto eran todos lisos. Examinando con atención la parte opuesta, descubrí una piedra correspondiente, pero enteramente encubierta por los escombros. Faltaba en ambos lados la piedra superior de los quiciales o largueros: la encontré por allí cerca, e inmediatamente me resolví a cavar la parte enterrada con el fin de llevármela toda (Stephens, 2003: 264).
\end{abstract}

En el lugar del hallazgo, Catherwood realizó dibujos de las jambas (Stephens, 1843: láms. XXII y XIII), y hoy existen dos versiones de éstas presentadas por otros autores (Cfr. Pollock, 1980: figs. 333-334; Spinden, 1920: 389). Según Spinden, una de las secciones superiores de estas jambas se perdió mientras estuvo en la isla, pero la pieza fue restaurada y reintegrada como se ve actualmente en el museo.

\title{
Augustus Le Plongeon (1826-1908) y Alice Dixon (1851-1910)
}

Otro conjunto de artefactos de Yucatán fue producto de las exploraciones emprendidas por la excéntrica pareja formada por Augustus y Alice Le Plongeon, los descubridores del "Chac mool" de Chichén Itzá. Él era oriundo de la isla de Jersey, en Francia, aunque más adelante adquirió la nacionalidad estadounidense. El intrépido Augustus conoció a la joven inglesa Alice Dixon en Londres, y poco después, en 1873 , la pareja se casó y viajó a Yucatán para emprender una serie de estudios de carácter etnográfico y arqueológico. Prepararon bien su viaje al corazón de la península, y durante una estancia en Mérida aprendieron la lengua maya con peritos locales, como lo fue su gran amigo y tutor el padre Crescencio Carillo y Ancona, fundador del Museo Yucateco y más tarde obispo del estado (Desmond y Messenger, 1988: 19).

\footnotetext{
${ }^{5}$ Extracts transmitted to Dr. Wissler at request of President Osborn, from letter to Mrs. Schuler from Cornelia Cruger, 19 de enero de 1911, Archivo Histórico del AMNH, Acc. No. 1919-55.
} 
El legado intelectual de esta pareja resulta controvertido. Convencidos de que los mayas yucatecos eran una tribu perdida de Egipto, distorsionaban las evidencias arqueológicas e históricas para conformarlas con sus teorías. La gran mayoría de los investigadores de su época rechazó tales explicaciones por considerarlas fantasías, y la generación subsecuente demostró de manera innegable que no existía ningún fundamento real para su posición. Sin embargo, el trabajo documental realizado por ellos, sus fotografías, notas de campo y colecciones, han sido de gran valor para los estudios arqueológicos (ibid.: 131; Le Plongeon, 1886).

Cuando no se encontraban explorando ruinas en Yucatán, residían en Nueva York, por tanto, depositar los frutos de su investigación en el recinto neoyorquino fue para ellos un gesto natural. En la colección del AMNH existen objetos que proceden de dos temporadas de campo, una realizada entre los años 1875 y 1876 , y la segunda en 1883. Durante la primera llevaron a cabo su famosa exploración de la Plataforma de las Águilas y Jaguares, donde recuperaron la estatua de un personaje que ellos designaron como Chac mool. Por debajo de la estatua, en el relleno de la estructura, entre otros objetos, se recuperó una ofrenda de puntas de proyectil de gran calidad, la mayoría de pedernal claro y otras de piedra verde. En el museo se conservan actualmente 24 puntas (figura 5), que parecen haber sido donadas por Stephen Salisbury, presidente de la Sociedad de Anticuarios Americanos de Worcester, quien las adquirió en Nueva York junto con las fotografías y las cartas que explicaban el hallazgo:

reliquias, que se dice fueron tomadas de la excavación donde fue hallada la estatua llamada la tumba del capitán Chac Mool, ahora están en poder del autor, junto con cartas del doctor Le Plongeon referentes a las fotografias, al descubrimiento de la estatua y a las reliquias. Tales reliquias consisten en una urna ornamental de cerámica y dos platos del mismo material, puntas de flecha de pedernal de factura superior, y puntas de jade de forma peculiar (Salisbury, 1877: 142; traducción nuestra).

El plan original de Le Plongeon era enviar la estatua de Chac mool a la ciudad de Filadelfia para mostrarla en la Exhibición del Centenario Americano, pero éste fue frustrado por el gobierno mexicano, encabezado por el presidente Lerdo de Tejada, con base en la Ley de 1827 que prohibía la exportación de artefactos arqueológicos (Desmond y Messenger, 1988: 41-43). En su defecto, envió las fotografías y los artefactos asociados. Aunque podemos ubicar las 24 puntas de flecha (que según Salisbury eran "dos docenas" de pedernal y de "jade") en las colecciones del museo, las piezas cerámicas, así como las cartas y fotografías mencionadas no se encuentran en este acervo, y su paradero actual se desconoce.

El descubrimiento de la "tumba" de Chac mool — que Le Plongeon ubicaba dentro de la Plataforma de las Águilas y Jaguares - le sirvió para fundamentar su interpretación sobre el supuesto asesinato del llamado príncipe Coh, también conocido según el repertorio de apelativos inventados por esta pareja como Chac mool (Garra roja). El "mausoleo" de este príncipe "de origen egipcio" llevaba encima la estatua de un "leopardo moribundo con cabeza humana", que se suponía era uno 
de los aspectos del guerrero (figura 6). Le Plongeon sostenía que el asesino de Coh fue su propio hermano Aac, quien lo eliminó por celos. Aún más, consideraba que la prueba de ello eran las puntas de pedernal encontradas en la ofrenda debajo de la estatua, ya que ésta tenía tres profundos agujeros en la espalda, en alusión a las heridas causadas por las tres armas (Le Plongeon, 1896: 157-159). El autor publicó estas tres puntas, que en realidad son una selección de la ofrenda hallada (ibid.: lám. LXIII), y no proporciona explicación alguna de la presencia de las demás puntas de lanza aparecidas en el mismo lugar, en tanto solamente destacaba las evidencias que concordaban con su narrativa inventada (figura 7).

Años después, la pareja regresa a realizar otra excavación en una estructura cercana, hoy conocida como la Plataforma de Venus, pero denominada por ellos el "Mausoleo del sacerdote Cay" (este último nombre, que quiere decir "pez" en maya, surgió por las figuras de peces que aparecen esculpidas en las esquinas del edificio). Durante las exploraciones encuentran una escultura, un portaestandarte antropomorfo. El hallazgo se relataba así en una nota publicada en la prensa local de la época:

Después de atravesar cinco pisos, que en opinión del doctor, marcan cinco épocas geológicas, se encontró aquél una figura echada de espaldas, la que fue puesta en posición horizontal, representaba un ser semi-hombre y semi-mono, de $78 \mathrm{~cm}$ de altura, y que considerándolo en pie mediría cosa de 7 pies de elevación. [...] Hacia el sur, y algo más abajo, a los pies de esa figura, se hallaba una urna circular de piedra, que medía cosa de un metro de diámetro; la tapa de $15 \mathrm{~cm}$ de espesor, apenas pudieron resbalarla cuatro hombres con fuerza. Tal urna, al parecer, se encontraba vacía; pero en el fondo se halló un poco de tierra roja [...]. En medio de esta tierra, una bola de cristal como de una pulgada de diámetro, y que al verla los indios trabajadores exclamaron: iSastun!, que todavía parece usan los hmen-es, entre los aborígenes, y que al fijarse en ella pretenden ver las cosas ocultas. ${ }^{6}$

De acuerdo con los detallados registros de campo realizados por Le Plongeon, dentro de la urna se encontró también una cuenta alargada de jade. Esta pieza está actualmente en exhibición en el AMNH. Debajo, junto con los huesos de un animal pequeño, había dos puntas de proyectil de obsidiana orientadas hacia el sur, que también forman parte del acervo actual del museo (figura 8).

Finalmente, de su viaje a las costas orientales de la península de Yucatán se conserva un cántaro, cuya fotografía forma parte del archivo de Eduard Seler en Berlín. Al revisar la olla, encontramos en su interior una nota original, escrita por Alice en inglés, que dice: "Olla de agua de los antiguos habitantes enanos de la isla de Cozumel" (figura 9). Esta observación concuerda con la idea ampliamente extendida de que los pequeños templos o adoratorios que caracterizan el estilo de la Costa Oriental eran refugio de los aluxes.

\footnotetext{
${ }^{6}$ Revista de Mérida, 19 de enero de 1884, No. 602. Fragmento transcrito por Eduard Seler, Instituto Iberoamericano, Berlín, Archivo Seler, Caja "Yucatán II".
} 


\section{Teobert Maler (1842-1917)}

Especialmente reconocido por su labor en el descubrimiento y registro de numerosos sitios arqueológicos en la península, el austriaco Teobert Maler logró también reunir una colección representativa de piezas de la región. Conocemos parte de este conjunto gracias a varias imágenes provenientes del archivo personal de Eduard Seler, resguardado en el Instituto Iberoamericano de Berlín. En dichas fotografías, probablemente tomadas por Maler mismo, se ilustran vistas parciales de su colección, que debió haber sido considerable. En una de ellas se aprecian diversos excéntricos de pedernal hallados en Ticul, que después pasaron al acervo del AMNH a través del propio Seler (figura 10). Allí destaca, al centro de la imagen, una interesante efigie que representa un hombre jaguar recostado sobre una plancha de piedra, cuya ubicación actual no es conocida. Por tanto, consideramos que las fotografias de la colección de Maler constituyen una importante fuente documental para el rescate del patrimonio arqueológico de los mayas peninsulares.

Parece ser que debido a severas dificultades económicas en los últimos años de su vida, Maler tuvo que desprenderse de sus pertenencias, incluyendo dibujos, fotografías, y también la colección arqueológica, que pasaron entonces a manos de distintos personajes de la época (Willard, 1926: 24). En otra de las fotografias de Seler es posible apreciar la colección local del yucateco Ernesto Regil, donde aparece la misma pieza (figura 11); en este caso resulta difícil establecer quién de los dos fue el propietario original de la misma, aunque esperamos encontrar mayores datos al respecto al profundizar en las investigaciones de los archivos.

Otro de los ejemplares de la colección Regil, que aparece dentro de un plato en la misma foto, se encuentra actualmente en las bodegas del museo, y es un vaso con jeroglíficos esgrafiados en el borde, que también procedía de Ticul (figura 12). Por sus características parece pertenecer al estilo Chocholá, aunque la forma resulta poco común, debido al reborde que presenta la vasija en su parte media. El estilo Chocholá corresponde a una tradición de cerámica con engobe de apariencia cerosa, cuyos colores van del gris al café rojizo, que se distingue por su decoración grabada o excavada previa a la cocción; aunque los centros de manufactura no son conocidos por la falta de contextos primarios, su distribución se asocia fundamentalmente a la región Puuc, en el noroeste de la península de Yucatán, y cronológicamente se ha ubicado dentro del complejo cerámico Cehpech del Clásico Tardío o Terminal (Velázquez, 2007)

De acuerdo al análisis preliminar de la inscripción que corre bajo el borde, realizado por Erik Velázquez y Guillermo Bernal, ${ }^{7}$ parece estar compuesta por glifos formales, a pesar de que su factura es burda. El texto no presenta un orden ortodoxo de lectura, pues no se trata de una fórmula dedicatoria típica o Secuencia Primaria Estándar, como resulta frecuente en este tipo de vasos. No obstante,

\footnotetext{
${ }^{7}$ Comunicación personal, octubre 2008.
} 
fue posible identificar un patrón de repetición aunque no se pudo establecer el inicio del texto y tampoco una lectura fonética. Tomando un punto de inicio arbitrario se identificó la siguiente secuencia: 1) rostro antropomorfo, 2) cabeza de venado, 3) glifo che ?, 4) rostro antropomorfo, 5) cabeza de murciélago, 6) glifo che ?, 7) cabeza de venado, 8) glifo de bandas cruzadas, 9) cabeza de ave, 10) glifo che ?,11) rostro antropomorfo frontal. Dadas las características de la inscripción, así como su procedencia reportada, resulta factible que se trate de un ejemplar tardío dentro del propio estilo Chocholá.

\section{Edward Thompson (1857-1935)}

Finalmente, se conserva una pequeña muestra del controvertido trabajo del cónsul Edward Thompson, autor del dragado del Cenote Sagrado de Chichén Itzá (Sellen, 2007). En el museo hay algunos fragmentos de cuentas de jade que encontramos acompañadas por una nota manuscrita de la donante, Mrs. Bleeker, una dama que seguramente estuvo de visita en Chichén Itzá en los años veinte. En su nota dice: "Estas cuentas me fueron entregadas por una mujer indígena, la cuidadora de la hacienda del Sr. Thompson, en Chichén Itzá, Yucatán. Vienen del Cenote Sagrado, en noviembre de 1923. Mientras cerraba mi mano alrededor de ellas dijo: 'No lo diga al Sr. Thompson'”8 (figura 13). Y aquí podría aplicarse el conocido dicho popular: "Ladrón que roba a ladrón tiene cien años de perdón".

Los casos enumerados constituyen ejemplos ilustrativos de la forma en que el estudio de los antiguos registros y colecciones pueden ayudarnos a reconstruir contextos arqueológicos perdidos y aportar información histórica sobre la génesis de la disciplina arqueológica. Adicionalmente, ello permite apreciar en su justa medida y en situaciones concretas los esfuerzos intelectuales de personajes destacados y de coleccionistas locales poco conocidos por acercarse al legado de los antiguos pueblos mayas.

\section{Agradecimientos}

Deseamos expresar nuestro reconocimiento a Elise Alexander y Kristen Mabel del Museo Americano de Historia Natural en Nueva York por su ayuda para ubicar los materiales. En forma especial, queremos agradecer sinceramente a nuestros colegas, los epigrafistas Erik Velázquez y Guillermo Bernal, por sus ideas y comentarios sobre la inscripción jeroglífica; asimismo, el Mtro. Velázquez nos permitió amablemente la consulta de sus materiales no publicados sobre el estilo Chocholá.

\footnotetext{
${ }^{8}$ Edward H. Thompson, Archivo Histórico del AMNH, Acc. No. 1911-45.
} 


\section{BIBLIOGRAFÍA}

Balkansky, Andrew K.

2005 "Saville, Boas, and Anthropological Archaeology in Mexico", Mexicon XXVII (5): 86-91.

Charnay, Désiré

1884 "Mis descubrimientos en México y en la América Central", América pintoresca. Descripción de viajes al nuevo continente por los más modernos exploradores, Carlos Wiener, Doctor Crevaux, D. Charnay, etc., pp. 265-470. Barcelona: Montaner y Simon Editores.

Dauterman, Carl C.

1939 "The Strange Story of the Stephens Stones", Natural History 44: 288-96.

Desmond, Lawrence G. y Phyllis Mauch Messenger

1988 A Dream of Maya: Augustus and Alice Le Plongeon in Nineteenth Century Yucatán. Albuquerque: University of New Mexico Press.

Le Plongeon, Alice Dixon

1886 Here and There in Yucatán. Nueva York: J.W. Bouston.

Le Plongeon, Augustus

1896 Queen Móo and the Egyptian Sphinx. Nueva York: publicación del autor.

Pérez de Heredia, Eduardo J.

2000 "El edificio de las Manos Rojas de Kabah, Yuc. Datos para la cronología". Tesis de licenciatura en Arqueología, Universidad de Yucatán, Mérida.

Putnam, F. W.

1900 "The Mexican Hall of the American Museum of Natural History", Science, new series, vol. 11, no. 262 (Jan. 5, 1900): 19-21.

Pollock, Henry E.D.

1980 The Puuc. An Architectural Survey of the Hill Country of Yucatán and Northern Campeche. Memoirs of the Peabody Museum, vol. 19. Cambridge: Harvard University.

Roberts, Jennifer L.

$2000 \quad$ "Landscapes of Indifference: Robert Smithson and John Lloyd Stephens in Yucatán", The Art Bulletin, vol. 82, no. 3 (Sep., 2000): 544-567.

Salisbury, Stephen, Jr.

1877 "An Account of the Statue Called Chac-Mool, Discovered in Yucatan by Dr. Augustus Le Plongeon", Journal of the American Geographical Society of New York, vol. 9: 142-148. 
Sellen, Adam

2005 "La colección arqueológica del Dr. Fernando Sologuren", Acervos: Boletín de los Archivos y Bibliotecas de Oaxaca, vol. 7, núm. 29: 4-15. Oaxaca: Asociación Civil Amigos de los Archivos y Bibliotecas de Oaxaca.

2007 "Un ambiente de sospecha, el papel de los Estados Unidos en la exploración arqueológica de México durante el siglo xIx", Los Investigadores de la Cultura Maya, tomo II, núm. 15, pp. 508-517. Campeche: Universidad Autónoma de Campeche.

Spinden, Herbert J.

1920 "The Stephens Sculptures from Yucatán", Natural History, vol. 20: 379-387.

Stephens, John L.

1963 [1843] Incidents of Travel in Yucatán, vols. I y II. Nueva York: Dover Publications.

2003 [1843] Viaje a Yucatán 1841-1842, trad. Justo Sierra O'Reilly. México: FCE.

Trigger, Bruce

1985 "Writing the History of Archaeology", Objects and Others, Essays on Museums and Material Culture (History of Anthropology, vol. 3), pp. 218-235, George W. Stocking, Jr. (ed.). Madison: University of Wisconsin Press.

Velázquez, Erik

2007 "El valor artístico y epigráfico de la cerámica de estilo Chocholá-Maxcanú. Situación actual y reflexiones desde la Historia del Arte", ponencia presentada en el Curso-taller de escritura maya de la península de Yucatán. Posgrado en Estudios Mesoamericanos, Instituto de Investigaciones Filológicas, UNAM. México, 6 de julio de 2007.

Von Hagen, Victor Wolfgang

1990 Maya Explorer. John Lloyd Stephens and the Lost Cities of Central America and Yucatán. San Francisco: Chronicle Books.

Willey, Gordon R. y Jeremy A. Sabloff

1974 A History of American Archaeology. Londres: Thames and Hudson.

Willard, T. A.

1926 The City of the Sacred Well: Being a Narrative of the Discoveries and Excavations of Edward Herbert Thompson in the Ancient City of Chichén Itzá. Nueva York: The Century.

Worsaae, Jens Jacob Asmussen

1849 The Primeval Antiquities of Denmark, trad. William J. Thoms. Londres: J. H. Parker. 


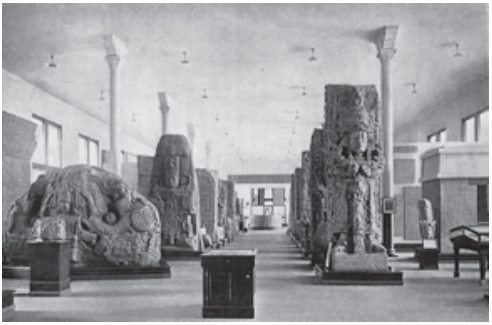

Figura 1. Sala de las Estelas, Museo Americano de Historia Natural, Nueva York, ca. 1900

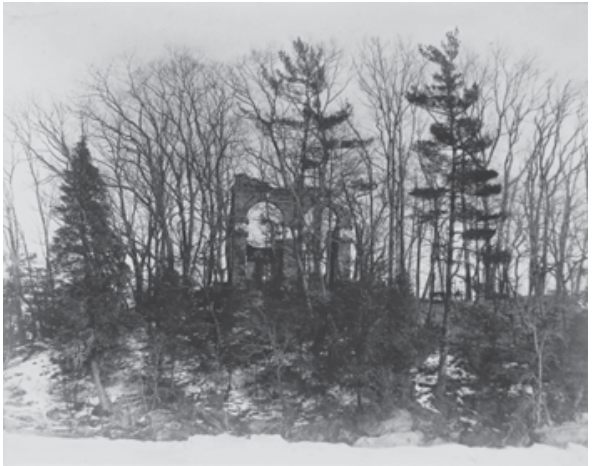

Figura 2. Estructura neogótica construida en la Isla Cruger, Nueva York, ca. 1919 


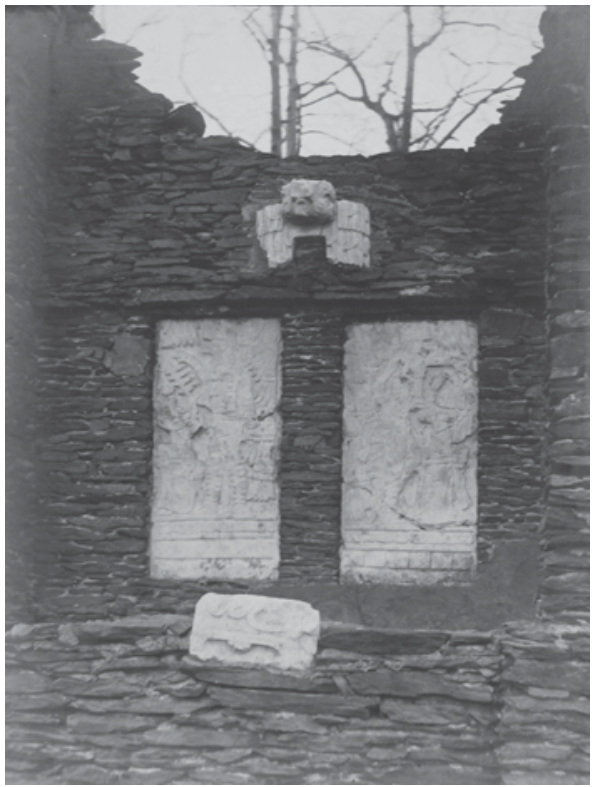

Figura 3. Piezas arqueológicas empotradas en la construcción de la Isla Cruger ca. 1919 


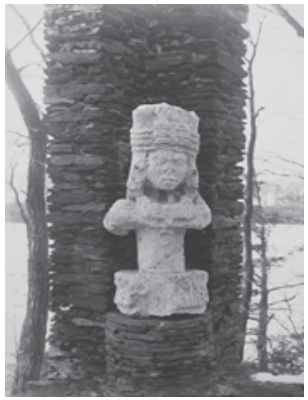

Figura 4. Escultura antropomorfa procedente de Uxmal, AMNH 30.0/4779

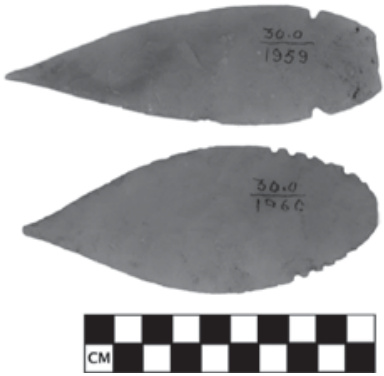

Figura 5. Puntas de sílex, AMNH 30.0/1959 y 30.0/1960 


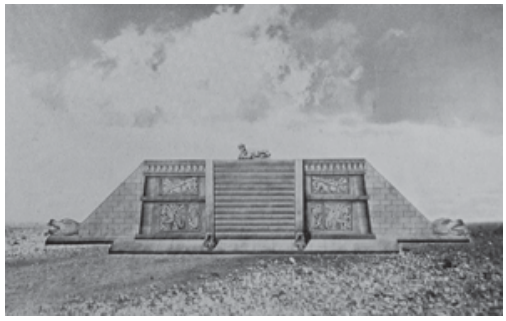

Figura 6. Plataforma de las Águilas y Jaguares de Chichén Itzá según Le Plongeon (1896: 155, lám. LVII)
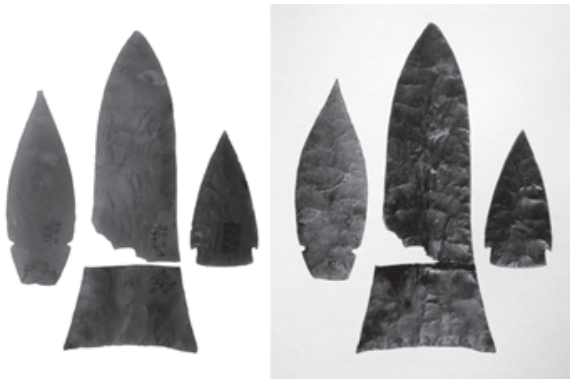

Figura 7. Comparación de los artefactos del AMNH (30.0/1951, 30.0/1946A, 30.0/1945B, 30.0/1964) con la fotografía de Le Plongeon (1886: 159, lám. LXIII) 

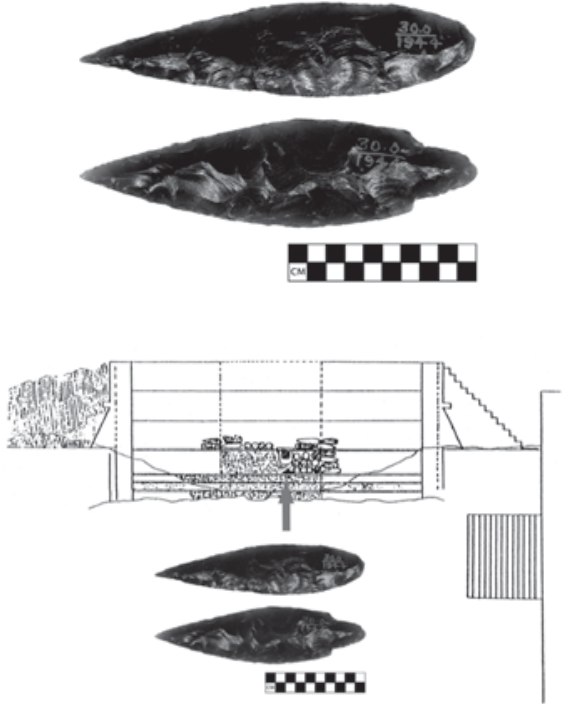

Figura 8. Puntas de obsidiana (30.0/1944A y 30.0/1944B) y corte realizado por Le Plongeon del lugar del hallazgo en el interior de la Plataforma de Venus, Chichén Itzá. Dibujo del corte reproducido de Desmond y Messenger (1988: 95) 


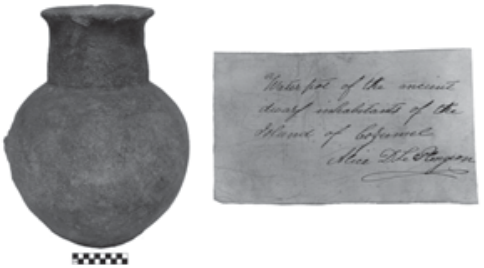

Figura 9. Cántaro de barro procedente de Cozumel (1/1988A) y nota manuscrita de Alice Le Plongeon hallada en su interior
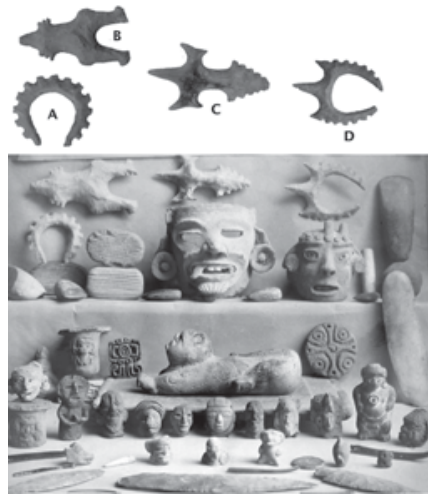

Figura 10. Colección de Teobert Maler y excéntricos procedentes de Ticul en el AMNH, A) $30.0 / 3020$; B) $30.0 / 3023$; C) $30.0 / 3021$; D) 30.0/3018. Foto: Colección Maler por cortesía del Instituto Iberoamericano de Berlín 


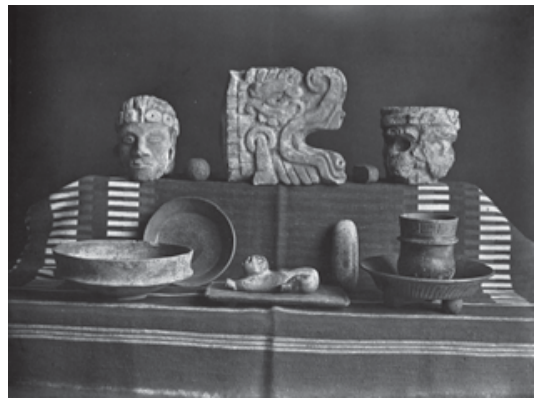

Figura 11. Colección de Ernesto Regil. Foto: cortesía del Instituto Iberoamericano de Berlín
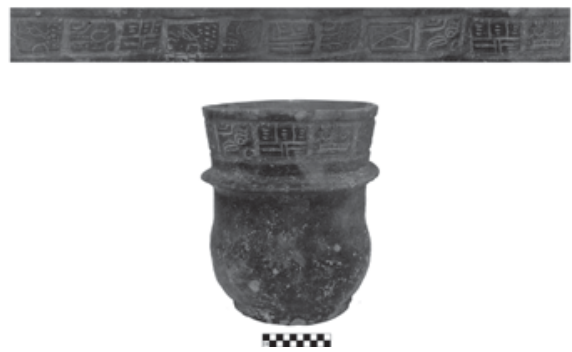

Figura 12. Vasija AMNH 30/1515. Foto: cortesía del Museo Americano de Historia Natural de Nueva York, fotografía de Adam Sellen 

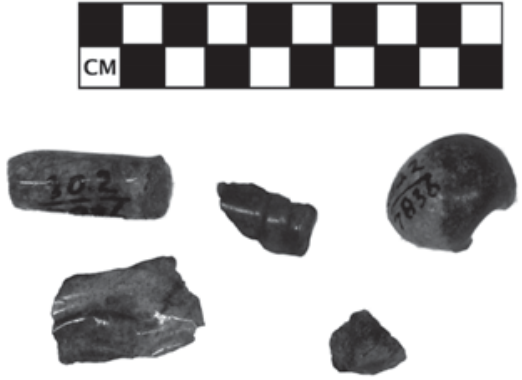

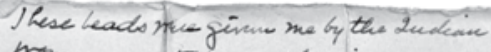

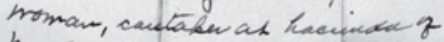

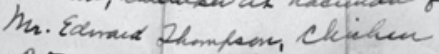

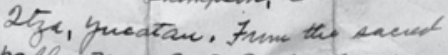
hele. Hor. 192 3. Gopke claced wey

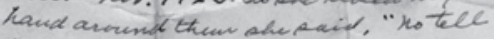
Me. 2emyew."

Figura 13. Cuentas de jade procedentes del Cenote Sagrado de Chichén Itzá 